Article

\title{
Winter Wheat Evapotranspiration Estimation under Drought Stress during Several Growth Stages in Huaibei Plain, China
}

\author{
Yi Cui ${ }^{1}$, Shangming Jiang ${ }^{2, * \mathbb{C}}$, Ping Feng ${ }^{1}$, Juliang Jin ${ }^{3}$ and Hongwei Yuan ${ }^{2}$ \\ 1 Stage Key Laboratory of Hydraulic Engineering Simulation and Safety, Tianjin University, \\ Tianjin 300072, China; cuiyi9007@tju.edu.cn (Y.C.); Fengping@tju.edu.cn (P.F.) \\ 2 Key Laboratory of Water Conservancy and Water Resources of Anhui Province, Water Resources Research \\ Institute of Anhui Province and Huaihe River Commission, Ministry of Water Resources, \\ Hefei 230088, China; yuanhw_1984@163.com \\ 3 School of Civil Engineering, Hefei University of Technology, Hefei 230009, China; JINJL66@126.com \\ * Correspondence: jiangshangming@163.com; Tel.: +86-0551-6577-1150
}

Received: 3 July 2018; Accepted: 22 August 2018; Published: 7 September 2018

\begin{abstract}
Estimating crop evapotranspiration under drought stress provides the theoretical foundation for optimizing irrigation schedule and reducing agricultural drought risk. Winter wheat water deficit plot experiments were conducted based on large-scale weighing lysimeters in the Huaibei Plain. The response of evapotranspiration to water deficit during several growth stages was analyzed; four crop coefficients were optimized and then evapotranspiration under drought stress was estimated with the dual crop coefficient method and the genetic algorithm. Drought stress not only reduced evapotranspiration during the current stage, but this influence was also transferred to the following periods. Evapotranspiration could basically return to the normal status after rewatering if the plant did not previously suffer from serious drought stress. Therefore, severe water deficit during continuous wheat growth periods should be avoided, and the deficit intensity during each stage should be controlled. The optimized $K_{c b}$ ini, $K_{c b \text { mid }}, K_{c b}$ end and $K_{c}$ max were 0.32 , $1.38,0.33$ and 1.39 , and the root mean square error, mean absolute error, and mean relative error of the corresponding estimated evapotranspiration under drought stress were $22.83 \%, 25.36 \%$, and $11.78 \%$ less than those using recommended coefficients, respectively. These optimized crop coefficients provide references for the practical application in the Huaibei Plain, this method for estimating crop evapotranspiration under drought stress can be applied to field circumstances and other regions.
\end{abstract}

Keywords: evapotranspiration; drought; dual crop coefficient; genetic algorithm; winter wheat

\section{Introduction}

Winter wheat is one of the main food crops in Anhui Province, China, and its perennial cultivated area is greater than two million hectares, and that in the Huaibei Plain accounts for approximately $70 \%$ of the total area. Meanwhile, according to the division of wheat planting districts in China, the Huaibei Plain belongs to the Huang-Huai winter wheat district [1], with a total annual yield of winter wheat that occupies approximately $8 \%$ of the national production; it is one of the most important winter wheat planting areas in China. However, the Huaibei Plain is located in a transitional zone of high and low latitudes with northern and southern climates [2], and its spatiotemporal distribution of precipitation is uneven, which results in frequent agricultural drought disasters. Moreover, in recent years, the probability and degree of continuous drought from winter to spring have become significant $[3,4]$. Therefore, deeply analyzing the response of winter wheat evapotranspiration to water deficit during several growth stages while accurately estimating the amount of evapotranspiration under drought 
stress is of great significance to formulating a reasonable irrigation program, improving water use efficiency and guaranteeing a high and stable yield of winter wheat in the Huaibei Plain $[5,6]$.

Since the 1980s, many scholars have carried out studies on the response of crop evapotranspiration via deficit irrigation experiments and have achieved valuable results. Cabelguenne et al. [7] researched the water consumption and its influence on yield for different crops, and put forward schemes for optimizing irrigation measures. Li et al. [8] made comparisons for the water requirement of rice between full and deficit irrigation practices and proposed the influence factors of rice evapotranspiration under different irrigation conditions. Peng et al. [9] researched the water requirement for field crops under water-saving irrigation and found that a water-saving irrigation program that guarantees high yields drastically reduced the crop evapotranspiration. Sincik et al. [10] discovered that evapotranspiration notably increased as irrigation water increased during the soybean growth period. Chen et al. [11] studied the effect of water deficits on tomato evapotranspiration at a single growth stage. However, only a few studies have been carried out regarding the response of crop evapotranspiration to drought stress during several growth stages.

The estimation of crop evapotranspiration under different irrigation conditions has always been popular in the farming and irrigation field and has been a concern by scholars [12-14]. The dual crop coefficient method [6,15], which is an empirical model recommended by the Food and Agricultural Organization of the United Nations (FAO) for estimating crop evapotranspiration [16], has been widely applied due to its easy operation, reliable precision and strong practicability, and it can separate evapotranspiration into crop transpiration and soil evaporation [17]. Currently, this estimation method is mainly used for estimating crop evapotranspiration without a water deficit [18,19]; however, because of the complexity of crop growth mechanism under water deficit situations, more studies should be further carried out regarding the estimation of crop evapotranspiration under drought stress in areas that frequently suffer from severe drought events, especially for drought stress during several crop growth stages $[6,20,21]$. Meanwhile, the basal crop coefficient $\left(K_{c b}\right)$ in the dual crop coefficient method recommended by the FAO has been determined based on the environmental conditions in a typical growing region, which may not be applicable for all climatic characteristics and crop species in the world [16,22]. Therefore, it is necessary to calculate the practical value of $K_{c b}$ according to actual meteorological data and irrigation experiment results for local crops in a research area. Similarly, due to the lack of specific crop irrigation experiment conditions and results, the maximum crop coefficient $\left(K_{c \max }\right)$ in the actual study region is difficult to precisely determine and it usually adopts the recommended value by the FAO when calculating crop evapotranspiration with the dual crop coefficient approach, which often results in a large deviation between the estimated and measured results $[16,23]$. In this study, winter wheat plot experiments under different deficit irrigation conditions during combined growth stages based on large-scale weighing lysimeters were conducted in the Huaibei Plain to (1) analyze the response of winter wheat evapotranspiration to drought stress during several growth stages, (2) estimate winter wheat evapotranspiration without water deficit condition via the dual crop coefficient method and calibrate and verify the relevant crop coefficients based on a genetic algorithm (GA), and then (3) estimate winter wheat evapotranspiration under drought stress situations through optimized crop coefficients. This study aims to discuss the winter wheat evapotranspiration response to drought stress during multiple growth periods and the compensation mechanism that occurs after rewatering, and to establish an applicable method for estimating crop evapotranspiration under drought stress conditions in field circumstances.

\section{Materials and Methods}

\subsection{Experimental Site}

The experiments were conducted in plots at the Xinmaqiao Agricultural Irrigation Research Station, Water Resources Research Institute of Anhui Province, and the Huai River Commission, China, which is located in Bengbu, north of the Huai River (latitude $33^{\circ} 09^{\prime} \mathrm{N}$, longitude $117^{\circ} 22^{\prime} \mathrm{E}$, altitude 
$19.7 \mathrm{~m}$ ) (Figure 1). This research site has a typical northern subtropical and warm, temperate transition zone climate, with a mean annual precipitation of $910 \mathrm{~mm}$, a mean pan evaporation of $916 \mathrm{~mm}$, a mean temperature of $15.0^{\circ} \mathrm{C}$, a mean relative humidity of $73 \%$, a mean sunshine duration of $1850 \mathrm{~h}$ and a mean frost-free period of $215 \mathrm{~d}$. The annual precipitation is unevenly distributed over the years, and drought disasters are common in this area. The experiment was implemented from October (sowing on 17 October 2013) to May (harvest on 23 May 2014), and the actual daily climatic conditions during the winter wheat whole growth period are shown in Figure 2.

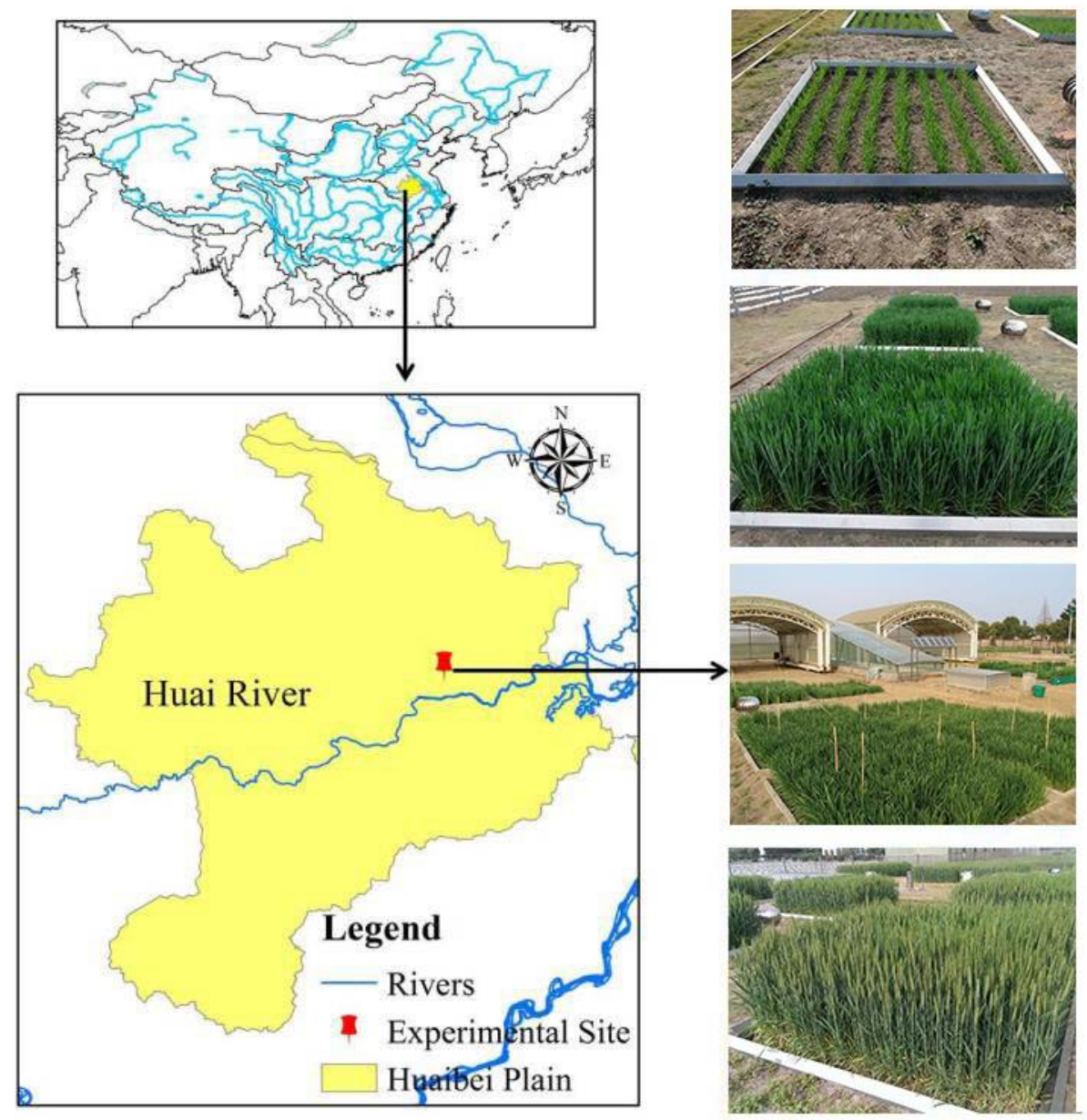

Figure 1. Location of the site in the Huaibei Plain and conditions of the winter wheat in plots.
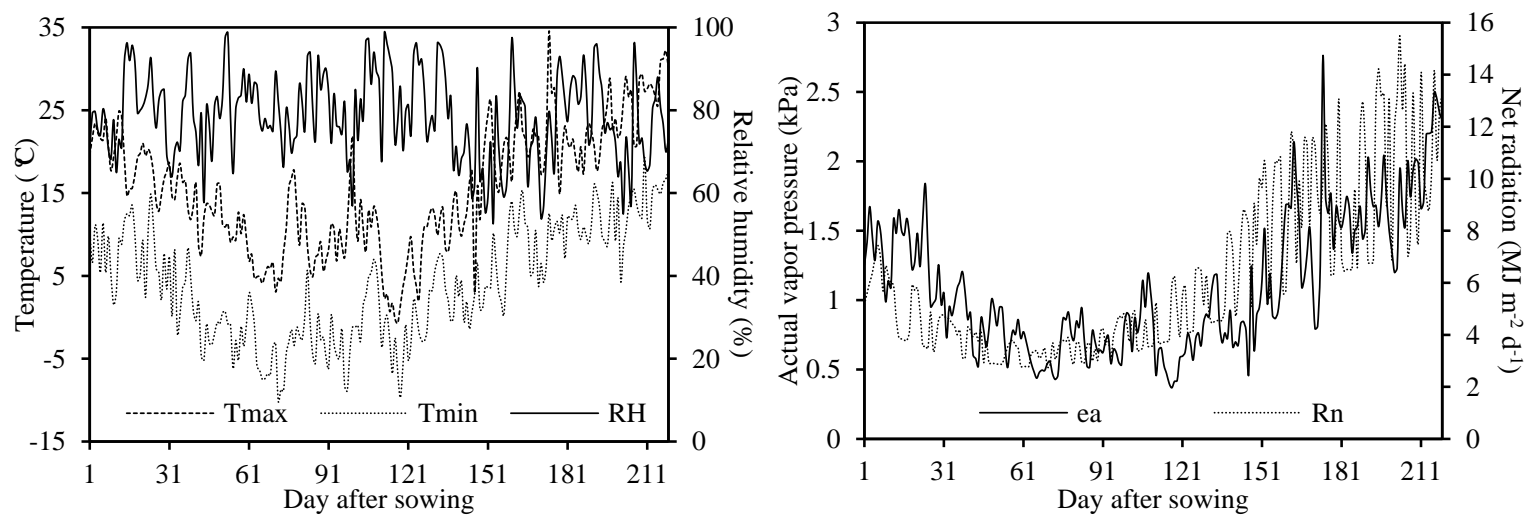

Figure 2. Climatic conditions of the experimental site during the winter wheat whole growth period. $\mathrm{T}_{\max }$ : maximum air temperature. $\mathrm{T}_{\min }$ : minimum air temperature. $R H$ : relative humidity. $e_{a}$ : actual vapor pressure. $R_{n}$ : net radiation. 


\subsection{Crop Management}

The experiment for quantitatively studying winter wheat evapotranspiration under drought stress was conducted based on large-scale weighing lysimeters; the size of each lysimeter was $2 \mathrm{~m}$ (length) $\times 2 \mathrm{~m}$ (width) $\times 2.3 \mathrm{~m}$ (depth). The lysimeters were prepared in the basement, and each irrigation treatment was set on an experimental plot on the ground above each lysimeter (Figure 1); the treatments were arranged randomly. Furthermore, there were 8 planting rows in each plot, and $13 \mathrm{~g}$ of wheat seeds were sown into each row. To ensure the germination of wheat seeds, the soil water content of the tillage layer in each plot was irrigated to field capacity after sowing with $240 \mathrm{~g}$ of compound fertilizer and $90 \mathrm{~g}$ of urea. The experimental soil was collected from a field tillage layer at this station and was typical Shajiang black soil from the Huaibei Plain. Its upper layer $(0-50 \mathrm{~cm})$ characteristics are shown in Table 1 . All experimental plots were placed in an open environment under a movable rain shelter that was closed when precipitation occurred (Figure 1). The soil water decreased with the winter wheat evapotranspiration and was supplied only by irrigation. Meanwhile, a $1.6 \mathrm{~m}$ width border between each plot was set to avoid the influence of lateral moisture migration. During the experimental period, with the exception of irrigation, other crop management practices, such as weeding and pest control, were the same for all experimental plot samples.

Table 1. Characteristics of experimental soil in the upper layer $(0-50 \mathrm{~cm})$.

\begin{tabular}{cc}
\hline Soil Characteristics & Value \\
\hline Sand (\%) & 3.45 \\
Silt (\%) & 70.52 \\
Clay (\%) & 26.03 \\
pH (in water solution) & 7.5 \\
Organic matter (\%) & 0.85 \\
Bulk density $\left(\mathrm{g} \mathrm{cm}^{-3}\right)$ & 1.36 \\
Field capacity at $-0.03 \mathrm{MPa}\left(\mathrm{cm}^{3} \mathrm{~cm}^{-3}\right)$ & 0.38 \\
Wilting point at $-1.5 \mathrm{MPa}\left(\mathrm{cm}^{3} \mathrm{~cm}^{-3}\right)$ & 0.12 \\
\hline
\end{tabular}

By combining relevant studies regarding winter wheat growth stages $[1,5,6]$ with practical winter wheat growth records from the station, the whole winter wheat growth period was divided into five single stages: the seedling stage (stage I, from 17 October 2013 to 18 November 2013), the tillering stage (stage II, from 19 November 2013 to 16 March 2014), the elongation stage (stage III, from 17 March 2014 to 8 April 2014), the heading stage (stage IV, from 9 April 2014 to 28 April 2014) and the milk-ripe stage (stage V, from 29 April 2014 to 23 May 2014) (Table 2).

Table 2. Lower limits of soil water content for different irrigation treatments during each winter wheat growth period.

\begin{tabular}{cccccc}
\hline Treatment & Stage I & Stage II & Stage III & Stage IV & Stage V \\
\hline T1 & $70 \%{ }^{1}$ & $55 \%$ & $55 \%$ & $70 \%$ & $45 \%$ \\
T2 & $70 \%$ & $45 \%$ & $45 \%$ & $45 \%$ & $70 \%$ \\
T3 & $70 \%$ & $55 \%$ & $45 \%$ & $55 \%$ & $55 \%$ \\
T4 & $70 \%$ & $55 \%$ & $55 \%$ & $70 \%$ & $55 \%$ \\
T5 & $70 \%$ & $55 \%$ & $55 \%$ & $55 \%$ & $45 \%$ \\
CK & $70 \%$ & $70 \%$ & $70 \%$ & $70 \%$ & $70 \%$ \\
\hline
\end{tabular}

${ }^{1}$ This number represents the percentage of the lower limit of soil water content relative to field capacity.

\subsection{Experimental Design}

In this experiment, six irrigation treatments (five deficit irrigation treatments and one full irrigation treatment) were conducted (Table 2), and there were three replications per treatment.

To assess and compare the influence of drought stress during several growth stages on winter wheat evapotranspiration, irrigation treatments with different water deficit levels at combined stages 
were designed. The treatments were implemented by setting different lower limits of soil water content in the experimental plots during different wheat growth stages. Based on the previous research $[10,24,25]$ and years of crop deficit irrigation experiments in this station, three lower limits of soil water content were set, which corresponded to no water deficit ( $70 \%$ of field capacity), slight water deficit ( $55 \%$ of field capacity), and serious water deficit ( $45 \%$ of field capacity), respectively. Meanwhile, to reflect the response of winter wheat evapotranspiration to the process of water deficit, to be close to the irrigation mode in actual crop production and to guarantee wheat survival, plants were irrigated to field capacity once the soil water content dropped below the lower limit [11]. In detail, no water deficit, slight and serious water deficits were set up during several wheat growth stages and were referred to as T1-T5. No water deficit was set up throughout the whole growth period, which was referred to as CK (Table 2).

\subsection{Measurements}

\subsubsection{Meteorological Data}

Wind speed at a height of $2 \mathrm{~m}$, maximum and minimum air temperature, relative humidity and sunshine duration were measured by the automatic weather station at the site; these data were collected every $5 \mathrm{~s}$ and recorded in a data acquisition unit every $15 \mathrm{~min}$.

\subsubsection{Plant Height}

The height of the winter wheat plant was measured by a flexible ruler approximately every 7 days after plant emergence, and the mean plant height during each growth stage was equal to the average of the measured results during that stage.

\subsubsection{Evapotranspiration}

Winter wheat evapotranspiration during the whole growth period was measured by large-scale weighing lysimeters (model QYZS-20, Xi'an Qingyuan Measurement \& Control Technology Co., Ltd., Xi'an, China), with a measurement accuracy of $0.02 \mathrm{~mm}$. The evapotranspiration data were automatically collected and recorded every hour by an information gathering system, and the daily evapotranspiration was equal to the sum during a $24-\mathrm{h}$ period.

\subsubsection{Soil Water Content}

The soil water content at $0-40 \mathrm{~cm}$ in the experimental plot was measured via sampling and drying approximately every 7 days, and a higher frequency of sampling was utilized during the stage when the wheat water consumption became larger. The soil water contents at $40 \mathrm{~cm}, 60 \mathrm{~cm}$ and $80 \mathrm{~cm}$ were collected by a soil moisture sensor. Finally, the soil water content in the plot was equal to the average of those from 0 to $80 \mathrm{~cm}$.

\subsubsection{Irrigation Amount}

Whether or not the wheat plant needed to be irrigated was determined by both the soil water content in the experimental plot and the lower limit of soil water content that corresponded to the irrigation treatment, and the irrigation amount was calculated using the following formula:

$$
I_{j}= \begin{cases}0 & \theta_{j-1} \geq \theta_{\mathrm{lm}} \\ 1000\left(\theta_{\mathrm{FC}}-\theta_{j-1}\right) \times Z_{r} & \theta_{j-1}<\theta_{\mathrm{lm}}\end{cases}
$$

where $\theta_{\mathrm{FC}}$ represents the soil water content at field capacity $\left(\mathrm{cm}^{3} \mathrm{~cm}^{-3}\right) ; \theta_{j-1}$ represents the mean soil water content in the experimental plot on day $(j-1)\left(\mathrm{cm}^{3} \mathrm{~cm}^{-3}\right) ; Z_{r}$ represents the effective rooting depth in the soil $(\mathrm{m})$, which had a value of $0.8 \mathrm{~m}$ in this study; $\theta_{\operatorname{lm}}$ represents the lower limit of the soil water content for each irrigation treatment $\left(\mathrm{cm}^{3} \mathrm{~cm}^{-3}\right)$; and $I_{j}$ represents the irrigation amount 
in the plot on day $j(\mathrm{~mm})$. In this experiment, the winter wheat plants were irrigated to $\theta_{\mathrm{FC}}$ on day $j$ when $\theta_{j-1}$ was lower than $\theta_{\mathrm{lm}}$. The irrigation amount was controlled by a water meter at the head of the pipeline.

\subsubsection{Yield Characteristics}

Winter wheat seed yield and the aboveground biomass (stem, leaf and seed) of all plants in each plot were measured at harvest time, and four groups of 1000 seed weight was randomly selected and measured. Seed yield and aboveground biomass were both measured after drying in the sun.

\subsection{Evapotranspiration Estimation by Combining the Dual Crop Coefficient Method with the Genetic Algorithm}

Winter wheat evapotranspiration was estimated based on the dual crop coefficient approach as follows [14,15]

$$
E T_{c}=K_{c} E T_{0}=\left(K_{s} K_{c b}+K_{e}\right) E T_{0}
$$

where $E T_{c}$ represents the wheat evapotranspiration $(\mathrm{mm}) ; K_{c}$ is the winter wheat crop coefficient; $E T_{0}$ represents the reference crop evapotranspiration $(\mathrm{mm}) ; K_{s}$ is the soil water stress coefficient, which reflects the negative influence of soil water deficit in the root zone on crop transpiration and varies from 0 to 1 ( $K_{s}$ is equal to 1 when the soil moisture does not affect the crop normal growth); $K_{c b}$ is the basal crop coefficient, which is the ratio of $E T_{\mathcal{C}}$ to $E T_{0}$ when the surface soil layer is dry and the mean soil moisture in the root zone meets the water requirement for crop transpiration; and $K_{e}$ is the soil evaporation coefficient, which reflects the influence of increased soil evaporation during a short time on crop evapotranspiration that is caused by wet topsoil after irrigation or precipitation.

\subsubsection{Reference Crop Evapotranspiration}

Reference crop evapotranspiration was calculated by the FAO-56 Penman-Monteith equation [6]

$$
E T_{0}=\frac{0.408 \Delta\left(R_{n}-G\right)+\gamma \frac{900}{T+273} u_{2}\left(e_{s}-e_{a}\right)}{\Delta+\gamma\left(1+0.34 u_{2}\right)}
$$

where $\Delta$ represents the slope of the vapor pressure curve $\left(\mathrm{kPa}^{\circ} \mathrm{C}^{-1}\right) ; R_{n}$ represents the net radiation above the crop canopy $\left(\mathrm{MJ} \mathrm{m}^{-2} \mathrm{~d}^{-1}\right) ; G$ represents the soil heat flux $\left(\mathrm{MJ} \mathrm{m}^{-2} \mathrm{~d}^{-1}\right) ; \gamma$ is the psychrometric constant $\left(\mathrm{kPa}{ }^{\circ} \mathrm{C}^{-1}\right) ; T$ represents the daily mean air temperature $\left({ }^{\circ} \mathrm{C}\right) ; u_{2}$ represents the mean wind speed at a height of $2 \mathrm{~m}\left(\mathrm{~m} \mathrm{~s}^{-1}\right) ; e_{s}$ represents the saturation vapor pressure $(\mathrm{kPa}) ;$ and $e_{a}$ represents the actual vapor pressure $(\mathrm{kPa})$.

\subsubsection{Basal Crop Coefficient}

Based on the linearized basal crop coefficient curve in FAO-56, the entire winter wheat growth period should be divided into four growth periods: the initial period, development period, midseason period and late season period. Then, three primary basal crop coefficients could be determined: $K_{c b}$ during the initial period $\left(K_{c b}\right.$ ini $), K_{c b}$ during the midseason period $\left(K_{c b}\right.$ mid $)$, and $K_{c b}$ at the end of the late season period ( $K_{c b}$ end); the values of $K_{c b}$ during the development and late season periods were obtained via linear interpolation [16]. By combining relevant studies $[5,6]$ with the actual winter wheat growth situation in the experiment, these four periods utilized to construct the crop coefficient curve were divided. According to the suggestion of FAO-56 [16], the values of $K_{c b \text { ini }}, K_{c b}$ mid (sug) and $K_{c b}$ end under standard climatic conditions were $0.15,1.10$ and 0.30 , respectively. However, because the value of $K_{c b}$ mid (sug) was greater than 0.45 , and the mean minimum relative humidity $\left(R H_{\min }\right)$ during the winter wheat midseason period was not equal to $45 \%$, and the mean wind speed at a height of $2 \mathrm{~m}\left(u_{2}\right)$ during that period was not equal to $2.0 \mathrm{~m} \mathrm{~s}^{-1}$; the value of $K_{c b}$ mid (sug) was adjusted according to the actual climatic conditions at this research station (Table 3) [15] 


$$
K_{c b \text { mid }(\operatorname{adj})}=K_{c b \text { mid }(\operatorname{sug})}+\left[0.04\left(u_{2}-2\right)-0.004\left(R H_{\min }-45\right)\right]\left(\frac{h}{3}\right)^{0.3}
$$

where $K_{c b}$ mid (adj) is the adjusted basal crop coefficient during the wheat midseason period according to actual climatic conditions at this station; $h$ represents the mean plant height during that period $(\mathrm{m})$.

Table 3. Climatic conditions at the experimental site and wheat plant heights during four periods.

\begin{tabular}{ccccc}
\hline Winter Wheat Growth Period & Initial Period & Development Period & Midseason Period & Late Season Period \\
\hline $\begin{array}{c}\text { Mean wind speed at a height of } 2 \mathrm{~m}, \\
u_{2}\left(\mathrm{~m} \mathrm{~s}^{-1}\right)\end{array}$ & 1.71 & 2.11 & 2.02 & 1.72 \\
\hline $\begin{array}{c}\text { Mean minimum relative humidity, } \\
R H_{\text {min }}(\%)\end{array}$ & 47.42 & 52.09 & 49.20 & 45.09 \\
\hline Mean wheat plant height, $h(\mathrm{~m})$ & 0.15 & 0.35 & 0.65 & 0.90 \\
\hline
\end{tabular}

\subsubsection{Soil Evaporation Coefficient}

The evaporation from the soil among the wheat plants and the canopy was controlled by an acceptable level of energy in the surface soil and the evaporation capacity of the atmosphere. The soil evaporation intensity reached its peak after irrigation or precipitation, and it decreased when the surface soil layer dried. The soil evaporation coefficient was calculated as follows [15]

$$
K_{e}=\min \left[K_{r}\left(K_{c \max }-K_{c b}\right), f_{e w} K_{c \max }\right]
$$

where $K_{c \text { max }}$ is the maximum $K_{c}$ following irrigation or precipitation; $f_{e w}$ represents the fraction of soil that is fully saturated by irrigation or rain and is not covered by the wheat canopy; and $K_{r}$ is the reduction coefficient for soil evaporation, which is determined by the accumulated water depletion and was obtained as follows [15]

$$
K_{r}= \begin{cases}1 & D_{e, j-1} \leq R E W \\ \frac{T E W-D_{e, j-1}}{T E W-R E W} & D_{e, j-1}>R E W\end{cases}
$$

where $D_{e, j-1}$ represents the accumulated water depletion from the surface soil layer at the end of day $(j-1)(\mathrm{mm}) ; R E W$ represents the soil evaporation during the phase controlled by the atmosphere evaporation, which was $9 \mathrm{~mm}$ in this study [15]; TEW represents the total available evaporation from the surface soil layer during a drought period (mm), which was calculated as follows [15]

$$
T E W=1000\left(\theta_{\mathrm{FC}}-0.5 \theta_{\mathrm{WP}}\right) Z_{e}
$$

where $Z_{e}$ represents the effective depth of the surface soil layer $(\mathrm{m})$, by combining the recommended value from FAO-56 [16] with the actual soil condition in the experiment, this value was $0.1 \mathrm{~m}$ in this study; and $\theta_{\mathrm{WP}}$ represents the soil water content at wilting point $\left(\mathrm{cm}^{3} \mathrm{~cm}^{-3}\right)$.

$K_{c}$ max was obtained by the following formula [15]

$$
K_{c \max }=\max \left\{\left\{1.2+\left[0.04\left(u_{2}-2\right)-0.004\left(R H_{\min }-45\right)\right]\left(\frac{h}{3}\right)^{0.3}\right\},\left\{K_{c b}+0.05\right\}\right\}
$$

$f_{\text {ew }}$ was calculated as follows [15]

$$
f_{e w}=\min \left(1-f_{c}, f_{w}\right)
$$

where $f_{w}$ represents the fraction of the soil surface that is wetted by irrigation or rain, because the irrigation method in this experiment was flood irrigation, this value was 1.0 [16]; $f_{c}$ represents the fraction of the soil surface that is effectively covered by canopy, it was estimated as follows [15] 


$$
f_{c}=\left[\frac{K_{c b}-K_{c \min }}{K_{c \max }-K_{c \min }}\right]^{(1+0.5 h)}
$$

where $K_{c}$ min represents the minimum $K_{c}$ for dry soil without wheat plant cover, its value was 0.15 [15].

In the computational process for the soil evaporation coefficient, the accumulated water depletion from the surface soil layer at the end of day $j, D_{e, j}$, was calculated based on the daily soil water balance in the surface soil layer [15]

$$
D_{e, j}=D_{e, j-1}-\left(P_{j}-R O_{j}\right)-\frac{I_{j}}{f_{w}}+\frac{E_{j}}{f_{e w}}+T_{e w, j}+D P_{e, j}
$$

where $P_{j}$ represents the precipitation on day $j(\mathrm{~mm}) ; R O_{j}$ represents the precipitation runoff on day $j(\mathrm{~mm}) ; E_{j}$ represents the soil evaporation on day $j(\mathrm{~mm})$, and $E=K_{e} E T_{0}[14] ; T_{e w, j}$ represents the depth of wheat transpiration in the surface soil layer that is wetted and without canopy on day $j(\mathrm{~mm})$; and $D P_{e, j}$ represents the percolation through the surface soil layer on day $j(\mathrm{~mm})$. In this study, $T_{e w}$ was so small that it could be neglected [15], $P, R O$ and $D P_{e}$ were all equal to 0 due to the experimental controls.

\subsubsection{Soil Water Stress Coefficient}

The soil water stress coefficient was calculated by the following equation [6]

$$
K_{s}= \begin{cases}1 & D_{r} \leq R A W \\ \frac{T A W-D_{r}}{T A W-R A W} & D_{r}>R A W\end{cases}
$$

where $D_{r}$ represents the accumulated soil water depletion in the winter wheat root zone (mm); $T A W$ represents the total available soil water in the root zone $(\mathrm{mm})$; and $R A W$ represents the readily available soil water in the root zone $(\mathrm{mm})$, where $p$ was 0.55 in $R A W=p T A W$ in this study [16]. TAW was estimated as follows [15]

$$
\mathrm{TAW}=1000\left(\theta_{\mathrm{FC}}-\theta_{\mathrm{WP}}\right) Z_{r}
$$

In the computational process of the soil water stress coefficient, soil water depletion in the wheat root zone on day $j, D_{r, j}$, was calculated based on the daily soil water balance in the root zone [16]

$$
D_{r, j}=D_{r, j-1}-\left(P_{j}-R O_{j}\right)-I_{j}-C R_{j}+E T_{c, j}+D P_{j}
$$

where $C R_{j}$ represents the capillary rise of soil moisture on day $j(\mathrm{~mm})$, but there was no groundwater supply in this experiment, $C R$ was equal to $0 ; D P_{j}$ represents the deep percolation from the wheat root zone on day $j(\mathrm{~mm})$, which was collected through a water pipe prepared in the basement and measured by a measuring cup.

\subsubsection{Crop Coefficients Calibration Based on the Genetic Algorithm}

A parameter optimization model was built based on the estimation of winter wheat evapotranspiration under full irrigation condition (CK) with the dual crop coefficient method. In detail, basal crop coefficients $K_{c b}$ ini, $K_{c b}$ mid and $K_{c b}$ end and maximum crop coefficient $K_{c}$ max were used as optimization variables. The sum of the absolute errors between the daily observed and simulated $E T_{\mathcal{C}}$ in CK during 155 days served as an objective function; these days were randomly selected during each winter wheat growth stage. Then, a genetic algorithm (GA) [26] was applied to solve the objective function via programing in MATLAB (version R2014a, The Math Works Inc., Natick, MA, USA), and four crop coefficients were obtained. The specific solving process was expressed through Equation (15). In addition, the observed $E T_{c}$ in $C K$ during the remaining 64 days of the whole winter wheat 
growth period were used to verify the optimized crop coefficients, and then they were applied to simulate the wheat evapotranspiration under drought stress conditions.

$$
\begin{array}{r}
\min f\left(K_{c b \text { ini }}, K_{c b \text { mid }}, K_{c b \text { end }}, K_{c \max }\right)=\sum_{i=1}^{n}\left|E T_{c o, i}-E T_{c s, i}\left(K_{c b \text { ini }}, K_{c b \text { mid }}, K_{c b \text { end }}, K_{c \max }\right)\right| \\
\text { s.t. }\left\{\begin{array}{c}
\min K_{c b \text { ini }}<K_{c b \text { ini }}<\max K_{c b \text { ini }} \\
\min K_{c b \text { mid }}<K_{c b \text { mid }}<\max K_{c b \text { mid }} \\
\min K_{c b \text { end }}<K_{c b \text { end }}<\max K_{c b \text { end }} \\
\min K_{c \max }<K_{c \max }<\max K_{c \max }
\end{array}\right.
\end{array}
$$

where $E T_{c_{0}, i}$ represents the observed wheat evapotranspiration on the $i$ th day, which was randomly selected for the calibration of the crop coefficients under full irrigation (mm); $E T_{c s, i}$ represents the simulated wheat evapotranspiration on the $i$ th day with the dual crop coefficient method $(\mathrm{mm})$; $n$ represents the total number of days selected during each wheat growth stage, which was 155 in this study; and $\min K_{c}$ and $\max K_{c}$ represent the lower and upper limit values of the crop coefficient.

\subsection{Error Index for Evaluating Simulation Accuracy}

The root mean square error (RMSE) [19,21], mean absolute error $(M A E)[19,21]$ and mean relative error $(M R E)[17,19]$ were used to assess the applicability and accuracy of the aforementioned method for estimating winter wheat evapotranspiration. In addition, the smaller the values of RMSE, MAE or $M R E$, the less the error was between the observed and simulated $E T_{c}$, and the stronger the applicability of the estimation method.

$$
\begin{gathered}
R M S E=\sqrt{\frac{1}{m} \sum_{i=1}^{m}\left(E T_{c \mathrm{c}, i}-E T_{c \mathrm{~s}, i}\right)^{2}} \\
M A E=\frac{1}{m} \sum_{i=1}^{m}\left|E T_{c \mathrm{c}, i}-E T_{c \mathrm{~s}, i}\right| \\
M R E=\frac{1}{m} \sum_{i=1}^{m}\left(\left|E T_{c \mathrm{o}, i}-E T_{c \mathrm{c}, i}\right| / E T_{c \mathrm{o}, i}\right) \times 100 \%
\end{gathered}
$$

where $m$ represents the number of wheat growth days in the process of evapotranspiration estimation.

\section{Results and Discussion}

\subsection{Winter Wheat Evapotranspiration under Drought Stress Conditions during Several Growth Stages}

Figure 3 shows the variation in measured evapotranspiration $\left(E T_{c}\right)$ under different irrigation treatments during each winter wheat growth stage. Due to different water deficit conditions during the current or previous stages, $E T_{c}$ at the same stage differed greatly.

There was no water deficit, slight, and serious water deficit at stage II in CK, T1 and T2, respectively, and their variation trends in $E T_{c}$ at this stage were basically consistent. However, the $E T_{c}$ in T1 and T2 was obviously less than that in CK, and the gap in T2 was larger than that in T1 (Figure 3a); the $E T_{\mathcal{C}}$ in $\mathrm{T} 2$ was $25.63 \%$ less than that in CK, and that in T1 was only $9.84 \%$. Similarly, the $E T_{\mathcal{C}}$ at stage III in T3 was $2.12 \%$ less than that in T5 (Figure 3b), and the $E T_{c}$ at stage IV in T5 was $10.46 \%$ less than that in T4 (Figure 3c). Under the same water deficit conditions during the previous stages, wheat evapotranspiration under drought stress during the current stage was lower than that under full irrigation, and the gap increased with deficit intensity. Therefore, water deficit during the winter wheat growth period reduced evapotranspiration; the more serious the deficit, the more significant the reduction. Our findings were consistent with Li et al. [8] and Chen et al. [11], who studied rice and tomato evapotranspiration under deficit irrigation, respectively. The water status in wheat plant changed when it suffered from drought stress, which inevitably caused an alteration of its physiological 
function, such as the closure of leaf stomata and the restriction of leaf growth, which resulted in the reduction of evapotranspiration $[8,27]$.
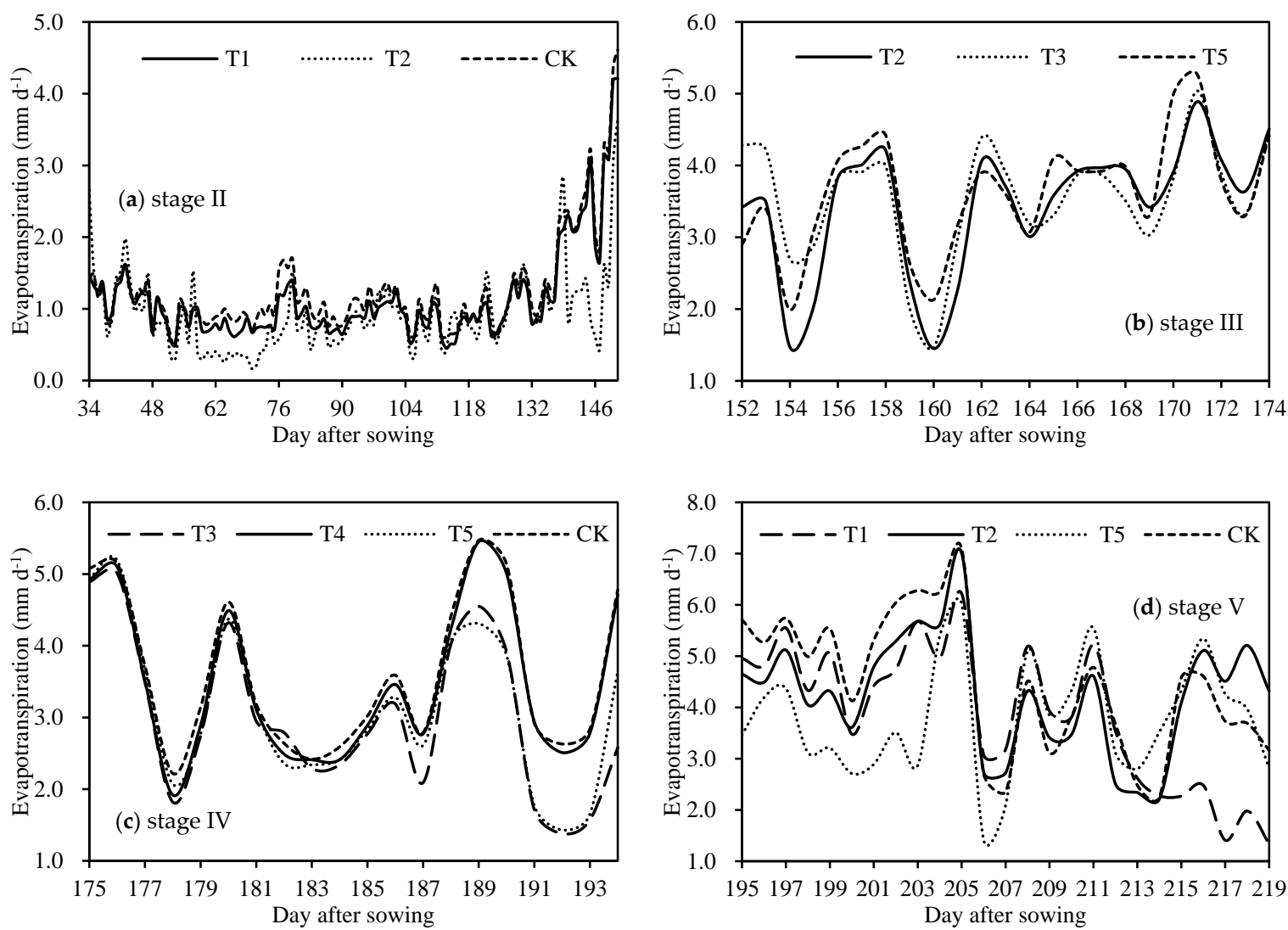

Figure 3. Observed daily wheat evapotranspiration during each growth stage for different treatments. (a) stage II: tillering stage; (b) stage III: elongation stage; (c) stage IV: heading stage; (d) stage V: milk-ripe stage.

There were serious and slight water deficits at stage II in T2 and T3, and they both suffered from serious water deficit at stage III. The daily $E T_{c}$ at stage III in T2 was significantly less than that in T3 (Figure $3 b$ ), and the $E T_{c}$ throughout stage III in T2 was 3.26\% less than that in T3. Similarly, the $E T_{c}$ at stage IV in T3 was $3.61 \%$ less than that in T5 (Figure $3 c$ ), and the $E T_{c}$ at stage $\mathrm{V}$ in $\mathrm{T} 5$ was $2.40 \%$ less than that in T2 (Figure 3d). Under the same water deficit conditions during the current stage, the evapotranspiration of winter wheat, which suffered from drought stress during the previous stages, was lower than that with full irrigation; the more serious the drought intensity during the previous stages, the more significant the additional reduction in evapotranspiration during the current stage. In other words, the water deficit during the current wheat growth stage not only had a negative influence on evapotranspiration at this stage, but it also had a cumulative effect that transferred this influence to evapotranspiration at the following periods. If the soil moisture could not be supplied in time, drought stress would further alter or damage the physiological function of wheat; therefore, water deficit during continuous stages should be prevented as far as possible in its growth process.

There were slight water deficits at stages II and III and no water deficit at stage IV in T4, its daily $E T_{c}$ at stage IV was close to that in $C K$, which was under full irrigation throughout the whole growth period (Figure 3c); the $E T_{c}$ at stage IV in T4 was only 3.25\% less than that in CK. However, for T2, which was under serious water deficit at stages II, III, and IV and no water deficit at stage V, its $E T_{c}$ at stage $V$ was $5.03 \%$ less than that in CK (Figure 3d), which was higher than the reduced percentage in $\mathrm{T} 4$ relative to $\mathrm{CK}$. Wheat evapotranspiration could basically return to the normal level via regaining full irrigation during the later growth periods if the plant did not suffer from serious drought stress 
at the previous stages, the influence of stress from the previous stages could be alleviated. This may reflect the ability for self-recovery of winter wheat. However, if the drought stress was serious, the physiological function of wheat may be irreversibly damaged, and the recovery result would not be desired. Therefore, reasonably controlling the deficit intensity during each winter wheat growth stage was vital for guaranteeing its recovery ability after rewatering, which provided a theoretical basis and practical guidance for formulating drought resistance measures. Li et al. [8] found that after rewatering, the water requirement intensity of rice was even larger than that under full irrigation. Peng et al. [9] pointed that the crop may generate adaptive ability in a temporary water deficit situation during its growth periods in the long process of evolution.

\subsection{Winter Wheat Yield Characteristics under Different Irrigation Treatments}

Table 4 shows the winter wheat yield characteristics under different irrigation treatments. The water deficit negatively affected the seed formation, and the seed yield loss increased with the deficit intensity during wheat growth stages. This was consistent with the response of evapotranspiration. The seed yield in T1 was lower than that in T4, while it was higher than that in T5. In addition, the total seed weights in T2, T3 and T5 were relatively lower. Compared to CK, the seed yield was reduced by $14.9 \%$ in $\mathrm{T} 2$, which was the largest reduction among deficit irrigation treatments. It indicated that the continuous drought stress during several wheat growth stages severely obstructed the seed formation, and the compensation abilities of rewatering after continuous serious water deficit from the tillering stage (stage II) to the heading stage (stage IV) was less effective. Meanwhile, adequate water supply at the heading stage was vital for guaranteeing the seed yield. In addition, the seed yield in T3 was higher than that in T5; therefore, the influence of serious water deficit at the milk-ripe stage (stage $\mathrm{V}$ ) on seed formation was greater than that at the elongation stage (stage III).

Table 4. Winter wheat aboveground biomass, seed yield, and 1000-seed weight under different irrigation treatments.

\begin{tabular}{cccc}
\hline Treatment & Aboveground Biomass $\left(\mathbf{t ~ h a}^{\mathbf{- 1}}\right)$ & Seed Yield $\left(\mathbf{t ~ h a} \mathbf{H}^{\mathbf{1}}\right)$ & $\mathbf{1 0 0 0}$ Seed Weight $\mathbf{( g )}$ \\
\hline T1 & 16.88 & 8.38 & 43.81 \\
T2 & 14.13 & 7.88 & 45.52 \\
T3 & 16.38 & 8.13 & 42.94 \\
T4 & 17.88 & 8.88 & 42.59 \\
T5 & 17.00 & 8.00 & 41.49 \\
CK & 18.00 & 9.25 & 45.59 \\
\hline
\end{tabular}

Similarly, the aboveground biomass and 1000 seed weight under water deficit conditions were lower than that under full irrigation. The drought stress during wheat growth stages decreased the amount of dry matter accumulation and the quality of single seed. The aboveground biomass at harvest in $\mathrm{T} 2$ was the lowest, this was consistent with the differences in the total seed weight. However, the 1000 seed weight in T2 approached that in CK, this could be because that the serious water deficit at the heading stage decreased the seed number and the full irrigation at the milk-ripe stage ensured or promoted the single seed accumulation. The 1000 seed weight in T5 was the smallest, which was reduced by $9.0 \%$ compared to $C K$, this could result from the limited seed number and single seed size caused by continuous drought stress from the heading stage to the milk-ripe stage.

\subsection{Estimation of Winter Wheat Evapotranspiration under No Drought Stress Condition}

Based on the estimation of winter wheat evapotranspiration without water deficit via the dual crop coefficient approach, the objective function was established, as shown in Equation (15); the genetic algorithm (GA) was applied to solve this function and four crop coefficients were optimized. A total of 155 days of observed $E T_{\mathcal{C}}$ samples in $C K$ were used for calibration, and the remaining 64 days of samples were used for verification. The estimated $E T_{c}$ based on the crop coefficients optimized 
by the GA (GA-estimated $E T_{c}$ ) were compared with those using the coefficients recommended by the FAO-56 (FAO-56-estimated $E T_{c}$ ). The RMSE, MAE and MRE of the GA-estimated $E T_{\mathcal{c}}$ during the phases of calibration and verification both reached a certain level of precision, and their values were all lower than those of FAO-56 (Table 5). Winter wheat evapotranspiration under no drought stress condition could be accurately simulated by using the optimized crop coefficients; the estimated precisions improved compared with the results using the coefficients suggested by the FAO-56 in general. The optimized crop coefficients were reliable; therefore, the estimation of evapotranspiration under drought stress could be further carried out.

Table 5. Root mean square error (RMSE), mean absolute error (MAE) and mean relative error (MRE) of estimated winter wheat evapotranspiration under full irrigation using crop coefficients that were optimized by the genetic algorithm (GA) and recommended by the FAO-56.

\begin{tabular}{ccccccc}
\hline \multirow{2}{*}{$\begin{array}{c}\text { Computational } \\
\text { Process }\end{array}$} & \multicolumn{2}{c}{$R M S E\left(\mathrm{~mm} \mathrm{~d}^{-\mathbf{1}}\right)$} & \multicolumn{2}{c}{$M A E\left(\mathrm{~mm} \mathrm{~d}^{-\mathbf{1}}\right)$} & \multicolumn{2}{c}{$M R E(\%)$} \\
\cline { 2 - 7 } & FAO-56 & GA & FAO-56 & GA & FAO-56 & GA \\
\hline Calibration & 0.43 & $\mathbf{0 . 2 4}$ & 0.30 & $\mathbf{0 . 1 8}$ & 13.88 & $\mathbf{1 1 . 2 0}$ \\
Verification & 0.53 & $\mathbf{0 . 3 0}$ & 0.37 & $\mathbf{0 . 1 8}$ & 12.50 & $\mathbf{7 . 6 2}$ \\
\hline
\end{tabular}

Figure 4 shows the observed and simulated daily $E T_{\mathcal{c}}$ under full irrigation during the whole growth period. The maximum daily $E T_{c}$ was $7.10 \mathrm{~mm} \mathrm{~d}^{-1}$, which appeared at stage $\mathrm{V}$ (205 days after sowing), and the average daily $E T_{c}$ during stages I, II, III, IV and V were $1.21 \mathrm{~mm} \mathrm{~d}^{-1}, 1.25 \mathrm{~mm} \mathrm{~d}^{-1}$, $3.98 \mathrm{~mm} \mathrm{~d}^{-1}, 3.62 \mathrm{~mm} \mathrm{~d}^{-1}$ and $4.47 \mathrm{~mm} \mathrm{~d}^{-1}$, respectively; these results were consistent with the findings discovered by Zhang et al. [5] and Wang et al. [28]. The elongation stage (stage III), heading stage (stage IV) and milk-ripe stage (stage V) were the most vigorous development periods for wheat vegetative and reproductive growth, and the water requirement during these stages were large. However, during the later period of the milk-ripe stage, the leaves of wheat began to wilt and turn yellow, which resulted in the decline of plant transpiration intensity [28].

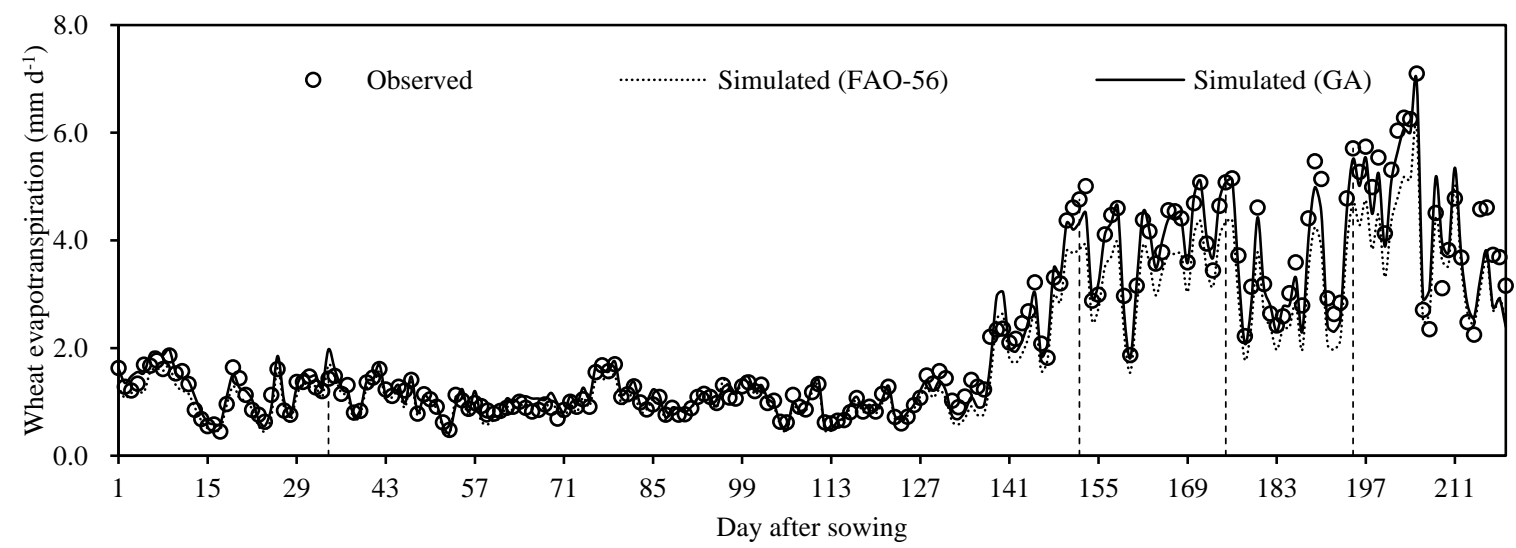

Figure 4. Observed and simulated daily winter wheat evapotranspiration under full irrigation during the whole growth period. Evapotranspiration is estimated based on the crop coefficients that are optimized by the genetic algorithm (GA) and recommended by the FAO-56. Stage I: seedling stage; stage II: tillering stage; stage III: elongation stage; stage IV: heading stage; stage V: milk-ripe stage.

The trends in simulated $E T_{c}$ during the whole growth period based on two types of crop coefficients both basically corresponded to the observed values, but the GA-estimated $E T_{c}$ was closer to the actual results. The GA-estimated $E T_{c}$ was larger than that of FAO-56 in general, especially after stage II (Figure 4). FAO-56-estimated $E T_{c}$ at stages I, II, III, IV and V were 12.02\%, 9.42\%, 14.83\%, $20.18 \%$ and $14.07 \%$ less than the measured results, respectively, and the RMSE, MAE and MRE at stages IV and V were relatively larger (Table 6). This indicated that there was a large deviation between 
the actual results and the estimated $E T_{c}$ using the crop coefficients recommended by the FAO-56, and the estimated values were small in general, especially during the heading stage and milk-ripe stage. However, GA-estimated $E T_{c}$ during the four stages were all close to the measured values; only the value at stage IV was $6.48 \%$ lower. $E T_{c}$ during the whole growth period was only $6.02 \mathrm{~mm}$ less than the observed result. Compared with FAO-56, the RMSE, MAE and MRE of GA-estimated $E T_{c}$ at each stage were smaller, and those during the whole growth period were $43.48 \%, 43.75 \%$ and $24.70 \%$ lower, respectively (Table 6). This reflected that the estimated $E T_{\mathcal{c}}$ using the crop coefficients optimized by the GA was closer to the actual values, and the estimated precision was significantly improved compared with the results that were based on the coefficients recommended by the FAO-56. Odhiambo and Irmak [29] considered that it was not suitable to estimate crop evapotranspiration by directly adopting the suggested crop coefficients. Lei and Yang [6] found that both the absolute and relative deviations between the observed and simulated evapotranspiration were quite large when the recommended coefficients were directly applied.

Table 6. Simulated wheat evapotranspiration $\left(E T_{c}\right)$ under full irrigation using the crop coefficients optimized by the genetic algorithm (GA) and recommended by the FAO-56, and the corresponding root mean square error (RMSE), mean absolute error (MAE) and mean relative error $(M R E)$.

\begin{tabular}{|c|c|c|c|c|c|c|c|c|c|}
\hline Growth Stage & $\begin{array}{l}\text { Observed } \\
E T_{c}(\mathrm{~mm})\end{array}$ & \multicolumn{2}{|c|}{ Simulated $E T_{c}(\mathrm{~mm})$} & \multicolumn{2}{|c|}{$R M S E\left(\mathrm{~mm} \mathrm{~d}^{-1}\right)$} & \multicolumn{2}{|c|}{$M A E\left(\mathrm{~mm} \mathrm{~d}^{-1}\right)$} & \multicolumn{2}{|c|}{$\operatorname{MRE}(\%)$} \\
\hline Stage I & 40.03 & 35.22 & 42.15 & 0.20 & 0.15 & 0.16 & 0.13 & 12.85 & 12.03 \\
\hline Stage III & 91.61 & 78.02 & 91.11 & 0.63 & 0.19 & 0.59 & 0.14 & 14.74 & 3.52 \\
\hline Stage IV & 72.35 & 57.75 & 67.66 & 0.77 & 0.31 & 0.73 & 0.27 & 20.26 & 7.86 \\
\hline Stage V & 111.82 & 96.09 & 107.96 & 0.85 & 0.55 & 0.74 & 0.45 & 15.90 & 11.65 \\
\hline
\end{tabular}

The crop coefficients which were recommended by the FAO-56 and optimized by the GA were compared. Compared with the suggested values, $K_{c b}$ ini, $K_{c b}$ mid and $K_{c}$ max optimized by the GA were obviously larger, and the $K_{c b}$ end was consistent (Table 7). Figure 5 shows the winter wheat crop coefficient curves during the whole growth period based on the suggested and optimized coefficients. The $K_{c b}$ and $K_{e}$ optimized by the GA were larger than those recommended by the FAO-56, and the trend in $K_{c b}$ was more obvious; therefore, according to Equation (2), the $K_{c}$ optimized by the GA were larger. This explained why the GA-estimated $E T_{c}$ were larger than those of FAO-56 in Figure 4. This showed that the suggested winter wheat crop coefficients were smaller than the actual values in this plot experiment, which was consistent with the findings discovered by Su et al. [23] in North China and those by Wang et al. [28] in the arid area of Northwest China. The underestimated crop coefficients mainly caused the estimated crop transpiration to decrease, and also made the estimated soil evaporation to be lower than the actual results. Therefore, accurate crop coefficients that correspond to the actual situations in the research area are necessary for applying the dual crop coefficient approach to estimate crop evapotranspiration. However, in this experiment, the actual $E T_{\mathcal{c}}$ in the entire plot was likely higher than that in field circumstances due to the oasis effects, which resulted from the dry bare soil borders between two plots (Figure 1). Meanwhile, the crop coefficients suggested by FAO-56 were mainly applicable for field scale, which caused that the optimized coefficients based on the observed values and the corresponding simulation $E T_{\mathcal{c}}$ were relatively larger than those of FAO-56. Therefore, there were differences between the optimized crop coefficients in this study and the actual results under field condition in the Huaibei Plain (the optimized ones could be relatively higher), but these values provided references for the practical production. Meanwhile, this estimation method could be applied to field circumstances when the field data were available. 
Table 7. Winter wheat crop coefficients suggested by the FAO-56 and optimized by the genetic algorithm (GA).

\begin{tabular}{ccc}
\hline Optimization Variable & FAO-56 Recommended & GA \\
\hline$K_{c b \text { ini }}$ & 0.15 & $\mathbf{0 . 3 2}$ \\
$K_{c b \text { mid }}$ & 1.09 & $\mathbf{1 . 3 8}$ \\
$K_{c b \text { end }}$ & 0.30 & $\mathbf{0 . 3 3}$ \\
$K_{c \text { max }}$ & 1.19 & $\mathbf{1 . 3 9}$ \\
\hline
\end{tabular}

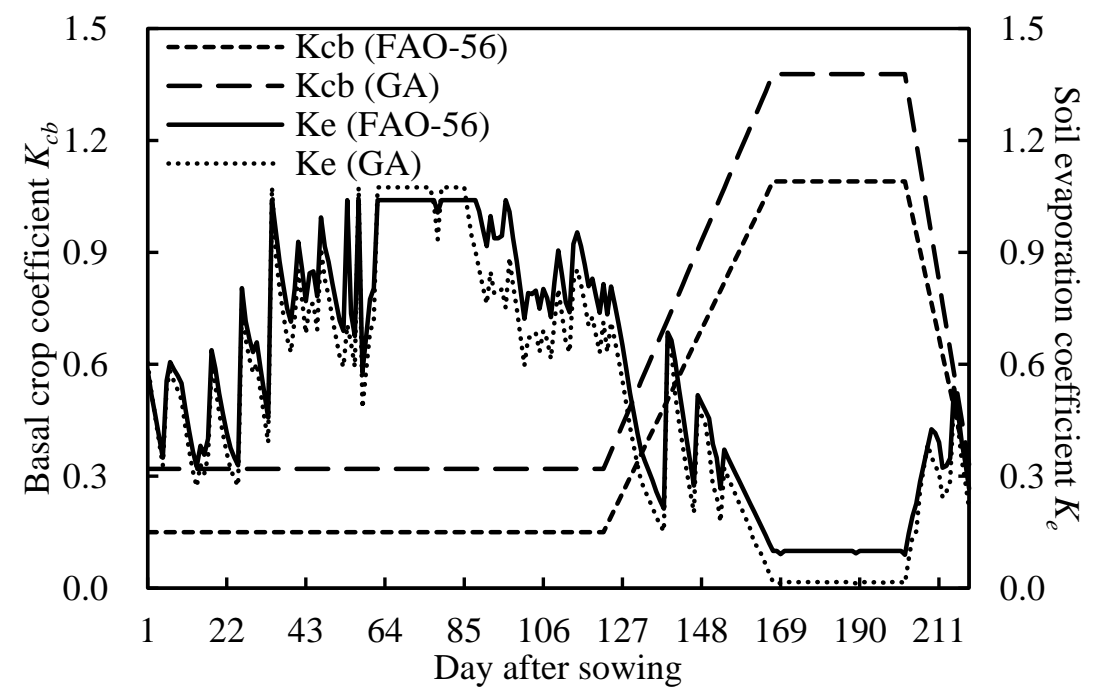

Figure 5. Winter wheat basal crop coefficient and soil evaporation coefficient curves during the whole growth period under full irrigation recommended by the FAO-56 and optimized by the genetic algorithm (GA).

\subsection{Estimation of Winter Wheat Evapotranspiration under Drought Stress Conditions}

Winter wheat evapotranspiration during each stage under five deficit irrigation treatments were estimated based on the aforementioned four optimized crop coefficients using the dual crop coefficient approach, which were compared against the results based on the suggested coefficients. Figure 6 shows the observed and simulated daily $E T_{c}$ in T1. The GA-estimated $E T_{\mathcal{c}}$ were closer to the measured values, and the FAO-56-estimtaed $E T_{\mathcal{c}}$ were significantly lower than the observed results (Figure 6). The GA-estimated $E T_{\mathcal{C}}$ during the whole growth stage was only $0.42 \%$ higher than the measured value, while the FAO-56-estimated result was $10.86 \%$ lower (Table 8). Figure 7 shows the observed and simulated daily $K_{c}$ in T5. The GA-estimated $K_{c}$ fit well with the actual results in general, but its values from 71-141 days after sowing (stage II) were lower than the measured results, while the values from 141-211 days after sowing (mainly including stages III and IV) were higher than the observed results (Figure 7). The trend in the FAO-56-estimated $K_{c}$ was the same as that for GA, but its values were obviously smaller, which corresponded to the estimated $E T_{c}$ in T5 (Table 8).

The RMSE, MAE and MRE of the GA-estimated $E T_{c}$ during each growth stage under five deficit irrigation treatments were all smaller than those of FAO-56. Meanwhile, the GA-estimated $E T_{\mathcal{c}}$ during each stage were slightly higher than the actual values in general, while the FAO-56-estimated results were smaller than the observed values (Table 8). From the perspective of the whole growth period, the average RMSE, MAE and MRE values of the GA-estimated $E T_{c}$ under five different drought stress conditions were $0.28 \mathrm{~mm} \mathrm{~d}^{-1}, 0.21 \mathrm{~mm} \mathrm{~d}^{-1}$ and $15.94 \%$, respectively, which were $22.83 \%, 25.36 \%$ and $11.78 \%$ less than the corresponding values via FAO-56. In addition, the GA-estimated $E T_{c}$ during the whole period were all higher than the observed values, the range was from $1.78-26.12 \mathrm{~mm}$ for all of the deficit treatments. In contrast, the FAO-56-estimated results were obviously lower than the actual values, and the range was from $25.57-45.93 \mathrm{~mm}$ (Table 8). By comparing the estimation error results 
in this study with Wang et al. [28] and Odhiambo and Irmak [29], winter wheat evapotranspiration under drought stress could be accurately estimated using the crop coefficients optimized by the GA, and the estimation precision significantly improved compared with the results based on the coefficients recommended by the FAO-56. Moreover, wheat evapotranspiration was obviously underestimated if the suggested coefficients were directly adopted, which could be due to that the crop coefficients recommended by FAO-56 were more suitable for field condition, and meanwhile the actual wheat evapotranspiration in this plot experiment was likely higher than that in field circumstances because of the oasis effects. This corresponded to the simulated results of wheat evapotranspiration under no drought stress when applying these two types of crop coefficients.

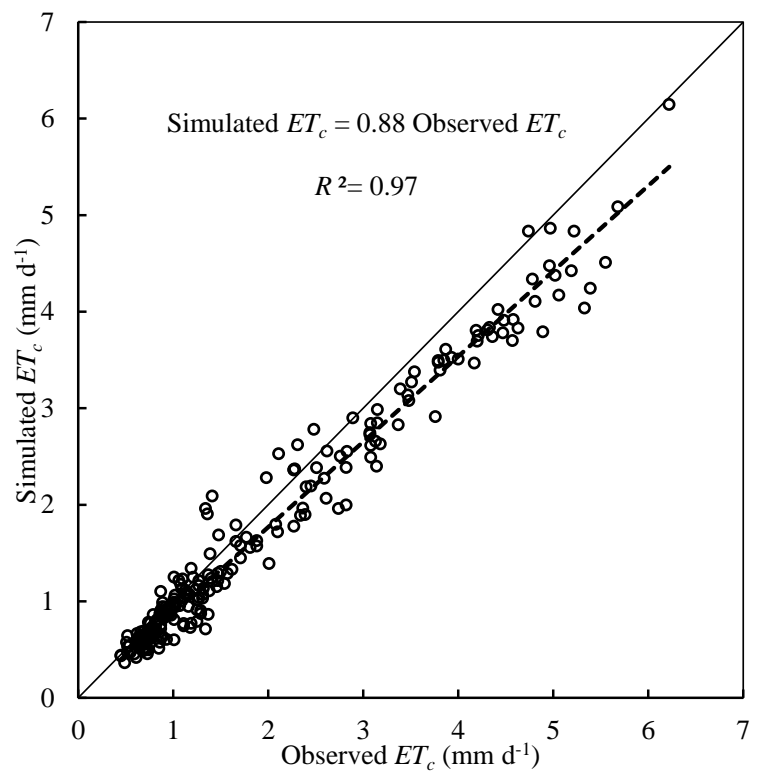

(a)

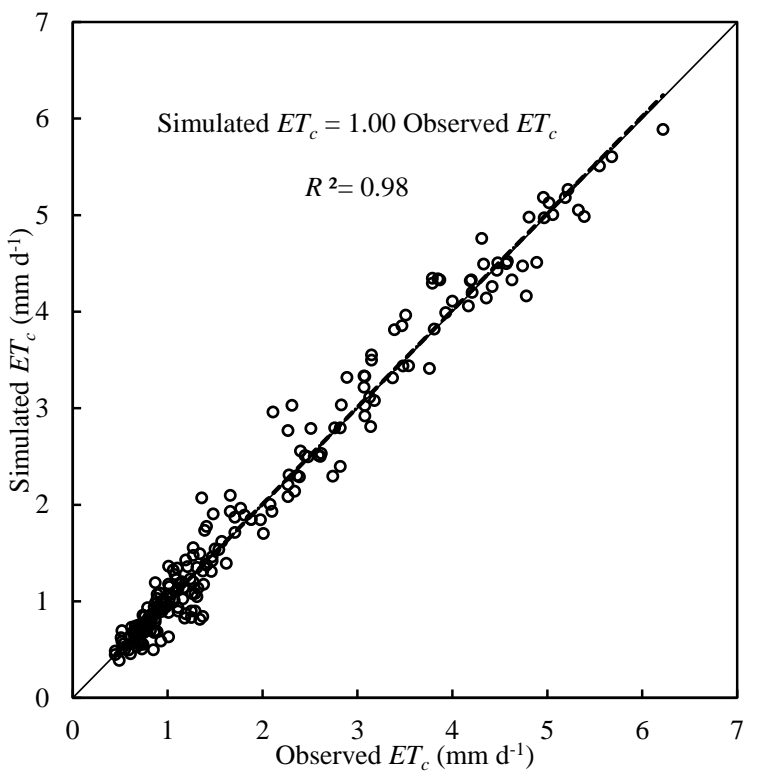

(b)

Figure 6. Comparison of observed and simulated daily winter wheat evapotranspiration $\left(\mathrm{ET}_{\mathrm{c}}\right)$ during the whole growth period in T1 using the crop coefficients (a) suggested by the FAO-56 and (b) optimized by the genetic algorithm (GA).

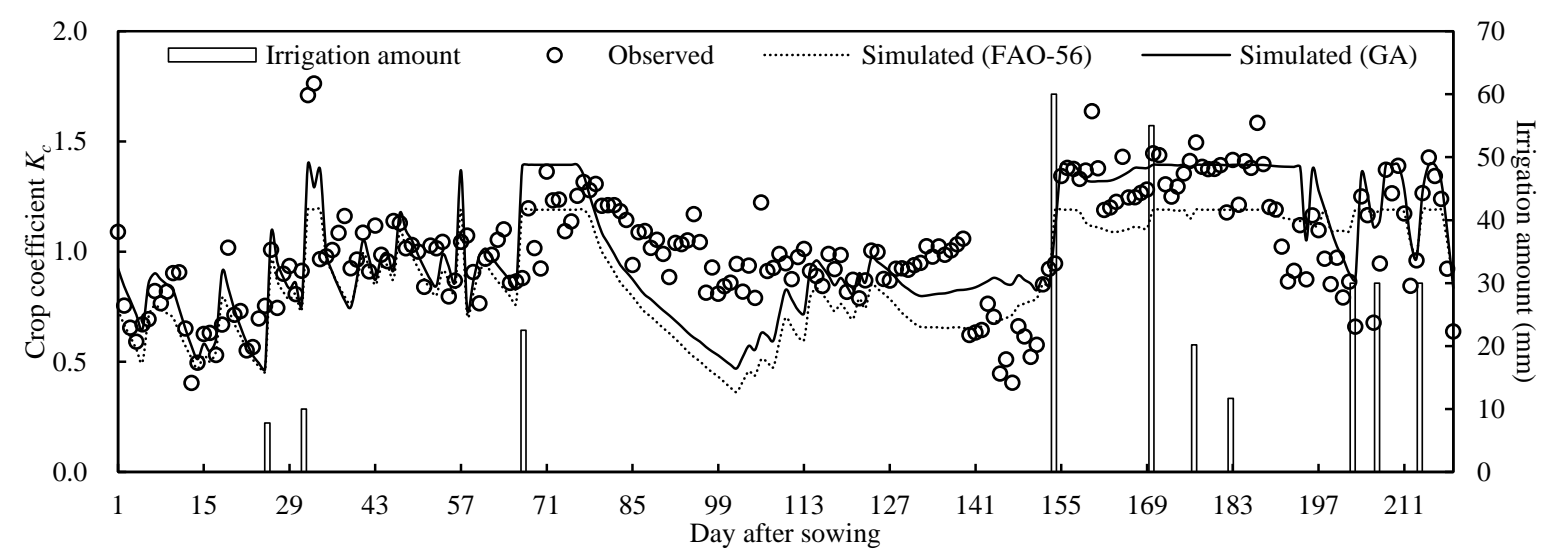

Figure 7. Observed and simulated daily winter wheat crop coefficient $\left(K_{c}\right)$ during the whole growth period in $\mathrm{T} 5$ using the crop coefficients recommended by the FAO-56 and optimized by the genetic algorithm (GA). 
Table 8. Estimated winter wheat evapotranspiration $\left(E T_{\mathcal{C}}\right)$ during each growth stage for different deficit irrigation treatments using the crop coefficients recommended by the FAO-56 and optimized by the genetic algorithm (GA), and the corresponding root mean square error (RMSE), mean absolute error (MAE) and mean relative error $(M R E)$.

\begin{tabular}{|c|c|c|c|c|c|c|c|c|c|c|}
\hline \multirow{2}{*}{ Treatment } & \multirow{2}{*}{ Growth Stage } & \multirow{2}{*}{ Observed $E T_{c}(\mathrm{~mm})$} & \multicolumn{2}{|c|}{ Simulated $E T_{c}(\mathrm{~mm})$} & \multicolumn{2}{|c|}{$R M S E\left(\mathrm{~mm} \mathrm{~d}^{-1}\right)$} & \multicolumn{2}{|c|}{$M A E\left(\mathrm{~mm} \mathrm{~d}^{-1}\right)$} & \multicolumn{2}{|c|}{ MRE (\%) } \\
\hline & & & FAO-56 & GA & FAO-56 & GA & FAO-56 & GA & FAO-56 & GA \\
\hline \multirow{6}{*}{$\mathrm{T} 1$} & Stage I & 40.67 & 36.92 & 42.21 & 0.20 & 0.18 & 0.16 & 0.12 & 12.45 & 10.32 \\
\hline & Stage II & 132.85 & 118.57 & 131.55 & 0.22 & 0.21 & 0.17 & 0.14 & 14.79 & 12.91 \\
\hline & Stage III & 83.44 & 74.05 & 88.21 & 0.48 & 0.33 & 0.41 & 0.28 & 10.76 & 7.83 \\
\hline & Stage IV & 69.48 & 57.30 & 66.64 & 0.67 & 0.29 & 0.62 & 0.23 & 17.82 & 7.10 \\
\hline & Stage V & 96.55 & 90.22 & 96.16 & 0.50 & 0.15 & 0.43 & 0.11 & 13.00 & 3.88 \\
\hline & Whole growth period & 422.99 & 377.06 & 424.77 & 0.36 & 0.22 & 0.26 & 0.16 & 14.08 & 10.42 \\
\hline \multirow{6}{*}{$\mathrm{T} 2$} & Stage I & 41.65 & 37.89 & 43.47 & 0.20 & 0.15 & 0.16 & 0.12 & 12.42 & 11.88 \\
\hline & Stage II & 109.59 & 94.73 & 105.68 & 0.30 & 0.28 & 0.22 & 0.20 & 24.72 & 23.97 \\
\hline & Stage III & 79.23 & 73.88 & 86.29 & 0.40 & 0.38 & 0.36 & 0.31 & 11.36 & 10.64 \\
\hline & Stage IV & 63.09 & 57.21 & 67.54 & 0.43 & 0.37 & 0.35 & 0.28 & 10.90 & 9.62 \\
\hline & Stage V & 106.19 & 99.49 & 113.22 & 0.38 & 0.33 & 0.32 & 0.28 & 7.35 & 7.33 \\
\hline & Whole growth period & 399.75 & 363.20 & 416.20 & 0.32 & 0.29 & 0.25 & 0.22 & 18.22 & 17.54 \\
\hline \multirow{6}{*}{$\mathrm{T} 3$} & Stage I & 42.14 & 37.15 & 42.61 & 0.21 & 0.19 & 0.17 & 0.15 & 14.61 & 13.24 \\
\hline & Stage II & 117.02 & 110.78 & 126.10 & 0.19 & 0.18 & 0.17 & 0.14 & 25.58 & 25.00 \\
\hline & Stage III & 81.90 & 76.05 & 87.44 & 0.35 & 0.30 & 0.30 & 0.25 & 8.14 & 7.96 \\
\hline & Stage IV & 60.42 & 57.15 & 66.01 & 0.48 & 0.41 & 0.41 & 0.29 & 14.75 & 12.70 \\
\hline & Stage V & 106.02 & 100.80 & 111.46 & 0.57 & 0.47 & 0.47 & 0.36 & 11.93 & 10.49 \\
\hline & Whole growth period & 407.50 & 381.93 & 433.62 & 0.31 & 0.27 & 0.24 & 0.19 & 19.55 & 18.66 \\
\hline \multirow{6}{*}{$\mathrm{T} 4$} & Stage I & 43.86 & 39.10 & 44.84 & 0.23 & 0.21 & 0.19 & 0.18 & 15.25 & 14.80 \\
\hline & Stage II & 116.65 & 106.23 & 118.50 & 0.31 & 0.30 & 0.21 & 0.20 & 21.20 & 20.32 \\
\hline & Stage III & 82.47 & 73.78 & 85.96 & 0.60 & 0.39 & 0.56 & 0.29 & 17.54 & 10.40 \\
\hline & Stage IV & 70.00 & 57.15 & 67.53 & 0.72 & 0.28 & 0.64 & 0.22 & 17.91 & 6.97 \\
\hline & Stage V & 97.23 & 88.51 & 99.85 & 0.57 & 0.20 & 0.47 & 0.16 & 11.27 & 4.85 \\
\hline & Whole growth period & 410.21 & 364.77 & 416.68 & 0.42 & 0.29 & 0.31 & 0.20 & 18.49 & 15.46 \\
\hline \multirow{6}{*}{$\mathrm{T} 5$} & Stage I & 43.84 & 37.15 & 42.61 & 0.34 & 0.27 & 0.23 & 0.17 & 15.85 & 14.87 \\
\hline & Stage II & 118.43 & 100.57 & 115.01 & 0.31 & 0.30 & 0.24 & 0.22 & 23.65 & 21.63 \\
\hline & Stage III & 83.67 & 73.78 & 86.33 & 0.53 & 0.28 & 0.47 & 0.25 & 13.42 & 7.31 \\
\hline & Stage IV & 62.68 & 57.15 & 67.53 & 0.47 & 0.45 & 0.40 & 0.32 & 13.54 & 13.35 \\
\hline & Stage V & 94.23 & 102.02 & 106.07 & 0.77 & 0.58 & 0.60 & 0.48 & 19.79 & 15.35 \\
\hline & Whole growth period & 402.85 & 370.67 & 417.55 & 0.43 & 0.35 & 0.32 & 0.26 & 20.03 & 17.64 \\
\hline
\end{tabular}




\subsection{Difference Analysis of Error Index for Evaluating Accuracy}

Figure 8 shows the average values of the error index for GA-estimated $E T_{c}$ during each growth stage under five deficit irrigation treatments. The stages that the small values of each error index corresponded to were different; RMSE was consistent with $M A E$, as their values were small at stages I and II, while MRE was small at stages III and IV. The results under full irrigation condition were basically the same as those previously mentioned (Table 6). This was attributed to the property of error index; RMSE and MAE were applied to evaluate the error from the perspective of absolute measure [30], which reflected the absolute amount of difference between the observed and simulated $E T_{c}$. The values of $R M S E$ and $M A E$ at the seedling stage and tillering stage were relatively small, which was mainly because the daily $E T_{c}$ during these two periods were low. However, $M R E$ was from the perspective of relative measure [30], its values at the heading stage and elongation stage were relatively small, which was primarily because of their large daily $E T_{c}$. Therefore, $R M S E, M A E$ and $M R E$ should be systematically considered when evaluating the simulated error.

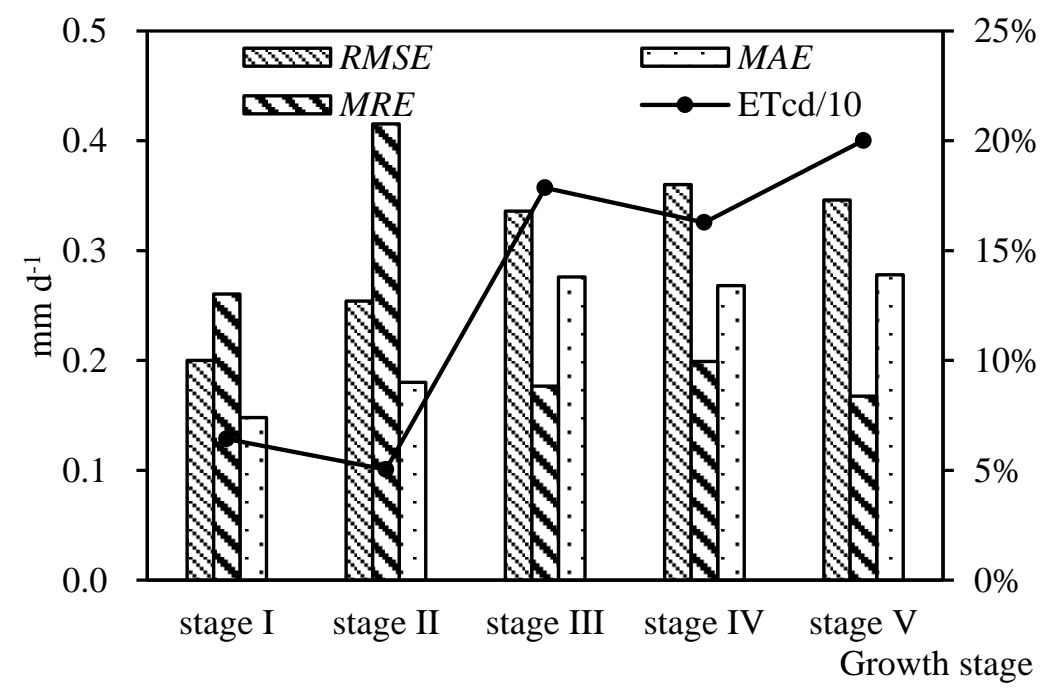

Figure 8. Average root mean square error (RMSE; $\left.\mathrm{mm} \mathrm{d}^{-1}\right)$, mean absolute error $\left(M A E ; \mathrm{mm} \mathrm{d}^{-1}\right)$, and mean relative error $(M R E ; \%)$ of estimated winter wheat evapotranspiration using the crop coefficients optimized by the genetic algorithm, and observed mean daily evapotranspiration $\left(E T_{c d}\right)$ during each growth stage for five deficit irrigation treatments. Stage I: seedling stage; stage II: tillering stage; stage III: elongation stage; stage IV: heading stage; stage V: milk-ripe stage.

Figure 9 shows the values of the error index for the GA-estimated $E T_{c}$ during the whole growth period under full irrigation treatment (CK) and five deficit irrigation treatments (T1-T5). The values of RMSE, MAE and MRE in CK were less than those in T1-T5, except for RMSE and MAE in T1, which indicated that the estimated $E T_{c}$ under drought stress conditions were not as good as those without water deficit in general when applying the dual crop coefficient approach. On the one hand, there were a fitting error and a verification error in CK, and there was only a verification error in T1-T5. On the other hand, due to the complexity of winter wheat growth mechanism under drought stress, it may be difficult to completely reflect the influencing processes of the drought stress during the current stage on the evapotranspiration during the current and following periods merely by the soil water stress coefficient. Therefore, it is necessary to further improve the dual crop coefficient approach based on a substantial number of crop water deficit experiments. 


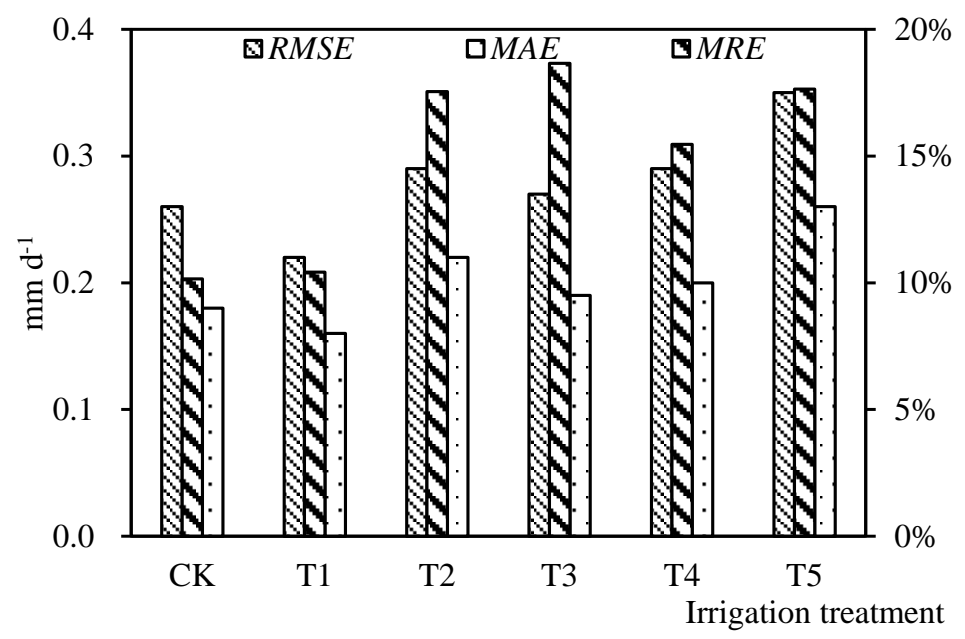

Figure 9. Root mean square error (RMSE; $\left.\mathrm{mm} \mathrm{d}^{-1}\right)$, mean absolute error $\left(M A E ; \mathrm{mm} \mathrm{d}^{-1}\right)$ and mean relative error $(M R E ; \%)$ of estimated winter wheat evapotranspiration using the crop coefficients optimized by the genetic algorithm during the whole growth period for different irrigation treatments. CK: full irrigation treatment; T1-T5: deficit irrigation treatments.

\section{Conclusions}

Winter wheat water deficit plot experiments were conducted in the Huaibei Plain based on large-scale weighing lysimeters; the response of winter wheat evapotranspiration to drought stress during several growth stages was analyzed; four crop coefficients were optimized and then evapotranspiration under water deficit were estimated.

Drought stress reduced winter wheat evapotranspiration; the more serious the drought intensity, the more significant the reduction. Meanwhile, drought stress during the current stage not only had a negative influence on the evapotranspiration at this stage, but it also had a cumulative effect that transferred this stress to evapotranspiration at the following periods; therefore, water deficit during continuous winter wheat growth stages should be prevented as far as possible in its growth process. In addition, wheat evapotranspiration could basically return to the normal level after rewatering during the later growth stage if the plant did not suffer from serious water deficit at the previous periods; this may reflect the ability for self-recovery of winter wheat. However, if the stress was serious, its physiological function may be irreversibly damaged, and the recovery result would be not desired. Therefore, reasonable controlling the deficit intensity during each winter wheat growth stage was vital for guaranteeing its recovery ability after rewatering, which provided a theoretical basis and practical guidance for formulating drought resistance measures.

Four winter wheat crop coefficients in the dual crop coefficient approach were optimized by the genetic algorithm (GA) based on the estimation of evapotranspiration under full irrigation; the optimized coefficients corresponded to practical winter wheat growth in this plot experiment, and the corresponding estimated evapotranspiration were closer to the actual results. Winter wheat evapotranspiration under drought stress in this experiment was accurately simulated using the optimized coefficients, and the estimation precisions were significantly improved compared with the estimated results when applying the coefficients recommended by the FAO- 56 . However, there were differences between the optimized crop coefficients in this study and the actual values under field conditions due to the limitation and influence of the plot experiment- the optimization results could be slightly higher than those in a field. In conclusion, the optimized crop coefficients could be referenced when estimating winter wheat evapotranspiration in the Huaibei Plain. The method for estimating crop evapotranspiration under drought stress situations based on the dual crop coefficient approach and the genetic algorithm was reasonable and reliable; it could be applied to field circumstances and other regions when the field data were available. 
Author Contributions: Y.C. and P.F. designed the experiment and wrote the paper; Y.C. and H.Y. completed the experiment and analyzed the experimental data; S.J. and J.J. contributed to the algorithm programming of the study. All authors read and approved the manuscript.

Funding: This research was funded by the [National Key Research and Development Program of China] grant number [2017YFC1502405] and the [National Natural Science Foundation of China] grant number [51579059 \& 51779165].

Acknowledgments: We are grateful for grants from the National Key Research and Development Program of China (2017YFC1502405) and the National Natural Science Foundation of China (51579059 \& 51779165).

Conflicts of Interest: The authors declare no conflicts of interest.

\section{References}

1. Li, Y.-C.; Huang, H.-P.; Ju, H.; Lin, E.-D.; Xiong, W.; Han, X.; Wang, H.-R.; Peng, Z.-P.; Wang, Y.-Q.; $\mathrm{Xu}, \mathrm{J}$.-W.; et al. Assessing vulnerability and adaptive capacity to potential drought for winter-wheat under the RCP 8.5 scenario in the Huang-Huai-Hai Plain. Agric. Ecosyst. Environ. 2015, 209, 125-131. [CrossRef]

2. Zhu, Y.-H.; Ren, L.-L.; Lü, H.-S.; Drake, S.; Yu, Z.-B.; Wang, Z.-L.; Fang, X.-Q.; Yuan, F. Effect of water table depth on growth and yield of soybean Yudou 16. J. Hydrol. Eng. 2013, 18, 1070-1076. [CrossRef]

3. Mishra, A.K.; Singh, V.P. Drought modeling-A review. J. Hydrol. 2011, 403, 157-175. [CrossRef]

4. Chang, J.-X.; Li, Y.-Y.; Wang, Y.-M.; Yuan, M. Copula-based drought risk assessment combined with an integrated index in the Wei River Basin, China. J Hydrol. 2016, 540, 824-834. [CrossRef]

5. Zhang, Y.-Q.; Yu, Q.; Liu, C.-M.; Jiang, J.; Zhang, X.-Y. Estimation of winter wheat evapotranspiration under water stress with two semiempirical approaches. Agron. J. 2004, 96, 159-168. [CrossRef]

6. Lei, H.-M.; Yang, D.-W. Combining crop coefficient of winter wheat and summer maize with remotely sensed vegetation index for estimating evapotranspiration in the North China Plain. J. Hydrol. Eng. 2014, 19, 243-251. [CrossRef]

7. Cabelguenne, M.; Debaeke, P.; Bouniols, A. EPICphase, a version of the EPIC model simulating the effects of water and nitrogen stress on biomass and yield, taking account of developmental stages: Validation on maize, sunflower, sorghum, soybean and winter wheat. Agric. Syst. 1999, 60, 175-196. [CrossRef]

8. Li, Y.-H.; Zhang, M.-Z.; Xie, L.-G.; Li, X.-J. Calculation of rice evapotranspiration under the condition of unsufficient irrigation. J. Hydraul. Eng. 1995, 2, 64-68. [CrossRef]

9. Peng, S.-Z.; Ding, J.-L.; Mao, Z.; Xu, J.-Z.; Li, D.-X. Estimation and verification of crop coefficient for water saving irrigation of late rice using the FAO-56 method. Trans. Chin. Soc. Agric. Eng. 2007, 23, 30-34.

10. Sincik, M.; Candogan, B.N.; Demirtas, C.; Büyükcangaz, H.; Yazgan, S.; Göksoy, A.T. Deficit irrigation of soya bean [Glycine max (L.) Merr.] in a sub-humid climate. J. Agron. Crop Sci. 2008, 194, 200-205. [CrossRef]

11. Chen, J.-L.; Kang, S.-Z.; Du, T.-S.; Qiu, R.-J.; Guo, P.; Chen, R.-Q. Quantitative response of greenhouse tomato yield and quality to water deficit at different growth stages. Agric. Water Manag. 2013, 129, 152-162. [CrossRef]

12. Kashyap, P.S.; Panda, R.K. Evaluation of evapotranspiration estimation methods and development of crop-coefficients for potato crop in a sub-humid region. Agric. Water Manag. 2001, 50, 9-25. [CrossRef]

13. Dejonge, K.C.; Ascough, J.C.; Andales, A.A.; Hansen, N.C.; Garcia, L.A.; Arabi, M. Improving evapotranspiration simulations in the CERES-Maize model under limited irrigation. Agric. Water Manag. 2012, 115, 92-103. [CrossRef]

14. Paredes, P.; D'Agostino, D.; Assif, M.; Todorovic, M.; Pereira, L.S. Assessing potato transpiration, yield and water productivity under various water regimes and planting dates using the $\mathrm{FAO}$ dual $\mathrm{K}_{\mathrm{c}}$ approach. Agric. Water Manag. 2018, 195, 11-24. [CrossRef]

15. Allen, R.G.; Pereira, L.S.; Smith, M.; Raes, D.; Wright, J.L. FAO-56 dual crop coefficient method for estimating evaporation from soil and application extensions. J. Irrig. Drain. Eng. 2005, 131, 2-13. [CrossRef]

16. Allen, R.G.; Pereira, L.S.; Raes, D.; Smith, M. Crop evapotranspiration: Guidelines for computing crop water requirements. In Irrigation and Drainage; Paper No. 56; FAO: Rome, Italy, 1998.

17. Martins, J.D.; Rodrigues, G.C.; Paredes, P.; Carlesso, R.; Oliveira, Z.B.; Knies, A.E.; Petry, M.T.; Pereira, L.S. Dual crop coefficients for maize in southern Brazil: Model testing for sprinkler and drip irrigation and mulched soil. Biosyst. Eng. 2013, 115, 291-310. [CrossRef] 
18. Phogat, V.; Šimůnek, J.; Skewes, M.A.; Cox, J.W.; McCarthy, M.G. Improving the estimation of evaporation by the FAO-56 dual crop coefficient approach under subsurface drip irrigation. Agric. Water Manag. 2016, 178, 189-200. [CrossRef]

19. Paredes, P.; Pereira, L.S.; Rodrigues, G.C.; Botelho, N.; Torres, M.O. Using the FAO dual crop coefficient approach to model water use and productivity of processing pea (Pisum sativum L.) as influenced by irrigation strategies. Agric. Water Manag. 2017, 189, 5-18. [CrossRef]

20. Anderson, R.G.; Alfieri, J.G.; Tirado-Corbalá, R.; Gartung, J.; McKee, L.G.; Prueger, J.H.; Wang, D.; Ayars, J.E.; Kustas, W.P. Assessing FAO-56 dual crop coefficients using eddy covariance flux partitioning. Agric. Water Manag. 2017, 179, 92-102. [CrossRef]

21. Xu, J.-Z.; Lv, Y.-P.; Ai, L.-K.; Yang, S.-H.; He, Y.-P.; Dalson, T. Validation of dual-crop coefficient method for calculation of rice evapotranspiration under drying-wetting cycle condition. Paddy Water Environ. 2017, 15, 381-393. [CrossRef]

22. Abrisqueta, I.; Abrisqueta, J.M.; Tapia, L.M.; Munguía, J.P.; Conejero, W.; Vera, J.; Ruiz-Sánchez, M.C. Basal crop coefficients for early-season peach trees. Agric. Water Manag. 2013, 121, 158-163. [CrossRef]

23. Su, M.-S.; Li, J.-S.; Rao, M.-J. Estimation of crop coefficients for sprinkler-irrigated winter wheat and sweet corn using a weighing lysimeter. Trans. Chin. Soc. Agric. Eng. 2005, 21, 25-29.

24. Desclaux, D.; Huynh, T.; Roumet, P. Identification of soybean plant characteristics that indicate the timing of drought stress. Crop Sci. 2000, 40, 716-722. [CrossRef]

25. Patanè, C.; Cosentino, S.L. Effects of soil water deficit on yield and quality of processing tomato under a Mediterranean climate. Agric. Water Manag. 2010, 97, 131-138. [CrossRef]

26. Jin, J.-L.; Cheng, J.; Wei, Y.-M. Forecasting flood disasters using an accelerated genetic algorithm: Examples of two case studies for China. Nat. Hazards 2008, 44, 85-92. [CrossRef]

27. Jacobsen, S.E.; Liu, F.-L.; Jensen, C.R. Does root-sourced ABA play a role for regulation of stomata under drought in quinoa (Chenopodium quinoa Willd.). Sci. Hortic Amst. 2009, 122, 281-287. [CrossRef]

28. Wang, Z.-S.; Cai, H.-J.; Yu, L.-Y.; Wang, X.-W.; Shi, X.-H. Estimation of evapotranspiration and soil evaporation of winter wheat in arid region of Northwest China based on SIMDualKc model. Transac. Chin. Soc. Agric. Eng. 2016, 32, 126-136. [CrossRef]

29. Odhiambo, L.O.; Irmak, S. Evaluation of the impact of surface residue cover on single and dual crop coefficient for estimating soybean actual evapotranspiration. Agric. Water Manag. 2012, 104, 221-234. [CrossRef]

30. Moriasi, D.N.; Arnold, J.G.; Van Liew, M.W.; Bingner, R.L.; Harmel, R.D.; Veith, T.L. Model evaluation guidelines for systematic quantification of accuracy in watershed simulations. Trans. Asabe 2007, 50, 885-900. [CrossRef]

(C) 2018 by the authors. Licensee MDPI, Basel, Switzerland. This article is an open access article distributed under the terms and conditions of the Creative Commons Attribution (CC BY) license (http://creativecommons.org/licenses/by/4.0/). 